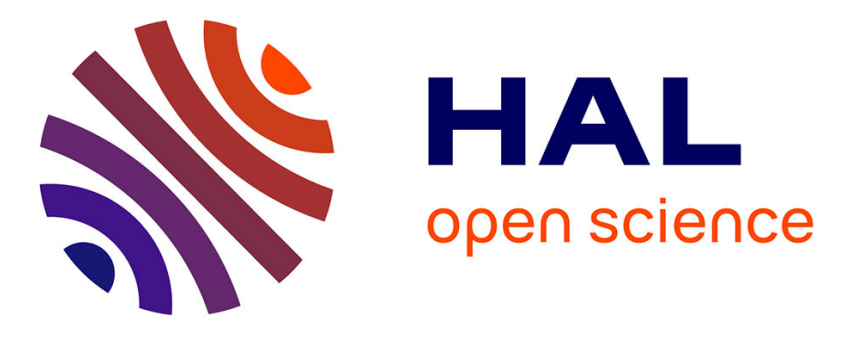

\title{
New Methods for Anomaly Detection: Run Rules Multivariate Coefficient of Variation Control Charts
}

Phuong Hanh H Tran, A. C. Rakitzis, H. D. Nguyen, Thong Nguyen, H Tran, Kim Phuc Tran, Cédric Heuchenne

\section{- To cite this version:}

Phuong Hanh H Tran, A. C. Rakitzis, H. D. Nguyen, Thong Nguyen, H Tran, et al.. New Methods for Anomaly Detection: Run Rules Multivariate Coefficient of Variation Control Charts. 2020 International Conference on Advanced Technologies for Communications, Oct 2020, Nha Trang, Vietnam. pp.40-44, 10.1109/ATC50776.2020.9255479 . hal-02968963

\section{HAL Id: hal-02968963 https://hal.science/hal-02968963}

Submitted on 16 Oct 2020

HAL is a multi-disciplinary open access archive for the deposit and dissemination of scientific research documents, whether they are published or not. The documents may come from teaching and research institutions in France or abroad, or from public or private research centers.
L'archive ouverte pluridisciplinaire HAL, est destinée au dépôt et à la diffusion de documents scientifiques de niveau recherche, publiés ou non, émanant des établissements d'enseignement et de recherche français ou étrangers, des laboratoires publics ou privés. 


\title{
New Methods for Anomaly Detection: Run Rules Multivariate Coefficient of Variation Control Charts
}

\author{
P. H. Tran*†, A. C. Rakitzis ${ }^{\ddagger}$, H. D. Nguyen*, Q. T. Nguyen ${ }^{\dagger \S}$, H. Tran*, K. P. $\operatorname{Tran}^{\S}$, and C. Heuchenne ${ }^{\dagger}$, \\ *Institute of Artificial Intelligence and Data Science, Dong A University, Da Nang, Vietnam \\ ${ }^{\dagger}$ HEC Liège, Management School of the University of Liège, Liège, Belgium \\ $\ddagger$ Department of Statistics \& Actuarial - Financial Mathematics, University of Aegean, Karlovasi, Greece \\ $\S$ GEMTEX Laboratory, Ecole Nationale Supérieure des Arts et Industries Textiles, Roubaix, France
}

\begin{abstract}
Among the anomaly detection methods, control charts have been considered important techniques. In practice, however, even under the normal behaviour of the data, the standard deviation of the sequence is not stable. In such cases, the coefficient of variation (CV) is a more appropriate measure for assessing system stability. In this paper, we consider the statistical design of Run Rules-based control charts for monitoring the CV of multivariate data. A Markov chain approach is used to evaluate the statistical performance of the proposed charts. The computational results show that the Run Rules-based charts outperform the standard Shewhart control chart significantly. Moreover, by choosing an appropriate scheme, the Run Rulesbased charts perform better than the Run Sum control chart for monitoring the multivariate $\mathrm{CV}$.
\end{abstract}

Index Terms-Anomaly Detection, Run Rules, Multivariate Coefficient of Variation, Control Chart, Markov Chain.

\section{INTRODUCTION}

Anomaly detection refers to the task of finding observations that do not conform to the normal, expected behaviour which is widely applied in research and in a variety of applications such as intrusion detection, fraud detection, and anomaly detection in wireless sensor networks, see [1], [2] for more details. Due to its significance, a large number of studies have been devoted to this problem in the literature. A survey in [3] provided an overview of anomaly detection techniques. Among several techniques proposed to handle the problem of anomaly detection, a control chart is considered a simple yet effective tool to detect anomalies in the data. Basically, a control chart includes a center line and control limits (upper and lower). A set of samples is taken online from the process to calculated the characteristic of interest. This value is then plotted in the control chart to monitor if the process is still in-control (when the statistic of interest is within control limits) or out-of-control (when the statistic of interest is beyond control limits). The first control chart introduced in the literature is the Shewhart control chart, which was named after the author [4]. Many other types of control charts have been proposed to improve the performance of the Shewhart control chart in detecting small shifts of a process such as the Cumulative Sum (CUSUM) control chart [5], the Run Sum control chart [6], the Run Rules control charts [7], etc.
Recently, the control charts become increasingly popular in anomaly detection techniques. For example, a control chart based on Kernel Null Space is used to detect intrusions of a network in real-time [8]. An overview of dynamic anomaly detection in social networks via control charts is presented [9].

The coefficient of variation (CV) is an important measure for assessing the stability of a process. Representing the ratio of the standard deviation to the mean, the coefficient of variation $(\mathrm{CV})$ is a useful measure of relative dispersion of a random variable. It has the meaning that the higher the $\mathrm{CV}$, the greater the level of dispersion around the mean. In many manufacturing processes, keeping the $\mathrm{CV}$ in-control means ensuring product quality. The first use of the Shewhart chart to monitor and detect changes in the $\mathrm{CV}$ is presented in [10]. In a process where two or more variables are considered simultaneously, this measure becomes the multivariate coefficient of variation (MCV). For example, in biometry and genetics, it is quite often to measure multiple characteristics on individuals from several populations and the problem is to assess the relative variability of each population. The single calculation of the univariate $\mathrm{CV}$ of each characteristic is obviously insufficient because it does not consider the correlation between these features, see [11].

A literature search reveals that not much attention has been paid to the $\mathrm{CV}$ for multivariate data despite its potential importance. The MCV control charts can only see in a few recent studies, for example, the Shewhart MCV control chart [12], the Run Sum MCV control chart [13], and the synthetic MCV control chart [14]. The goal of this paper is then to investigate the performance of the Run Rules control charts in detecting anomaly from a process based on the MCV characteristic. Compared to other control charts, the Run Rules charts have a simpler design (it only adds the supplementary Run Rules in the implementation of the Shewhart chart) but is still very effective at monitoring shifts from a process. This type of control chart is the major concern in several studies, see, for example, [15]-[18]. In fact, the Run Rules control charts have been proposed to monitor the MCV in [19]. However, only the 2 -of-3 and the 3 -of-4 run rules are considered in [19]. Meanwhile, it is well documented that the 
4-of-5 runs rule is more efficient than the previous ones in cont certain cases [20]. Therefore, we consider additionally the 4of-5 run rules in this study and provide a theoretical basis to extend the Run Rules control charts to the general case $r$ out-of-s. We also provide additional numerical comparisons between the most frequently used one-sided Shewhart-MCV charts with or without run rules. Numerical simulations show that our proposed charts are efficient in detecting the process shifts.

The paper is organised as follows. Section II provides a brief review of distribution of the sample MCV. In Section III, we present the design and implementation of the Run Rules control charts for monitoring the MCV. Section IV is devoted to assessing the performance of the proposed charts. Some concluding remarks are given in Section V.

\section{A BRIEF REVIEW ON THE DiSTRIBUTION OF THE SAMPLE MULTIVARIATE COEFFICIENT OF VARIATION}

We present a brief review of the distribution of the sample $\mathrm{MCV}$. From the literature, there are different point of views about the definitions of the MCV. A formal definition for the multivariate coefficient of variation was firstly proposed in [21]. Another definition of the MCV was given in [22] based on the Mahalanobis distance. We use the definition of the MCV suggested in [22] which is considered as a natural generalisation for the $\mathrm{CV}$. This definition was also adopted in [12] to monitor the MCV. Let $\mathbf{X}$ denote a random vector from a $p$-variate normal distribution with mean vector $\boldsymbol{\mu}$ and covariance matrix $\boldsymbol{\Sigma}$. The MCV is defined as

$$
\gamma=\left(\boldsymbol{\mu}^{T} \boldsymbol{\Sigma}^{-1} \boldsymbol{\mu}\right)^{-\frac{1}{2}}
$$

Suppose that a random sample of size $n$, say $\mathbf{X}_{1}, \mathbf{X}_{2}, \ldots, \mathbf{X}_{n}$, is taken from this distribution, i.e., $\mathbf{X}_{i}=\left(x_{i, 1}, x_{i, 2}, \ldots, x_{i, p}\right) \sim N(\boldsymbol{\mu}, \boldsymbol{\Sigma}), i=1, \ldots, n$. Let $\overline{\mathbf{X}}$ and $\mathbf{S}$ be the sample mean and the sample covariance matrix of $\mathbf{X}_{1}, \mathbf{X}_{2}, \ldots, \mathbf{X}_{n}$, i.e., $\overline{\mathbf{X}}=\frac{1}{n} \sum_{i=1}^{n} \mathbf{X}_{i}$, and $\mathbf{S}=\frac{1}{n-1} \sum_{i=1}^{n}\left(\mathbf{X}_{i}-\overline{\mathbf{X}}\right)\left(\mathbf{X}_{i}-\overline{\mathbf{X}}\right)^{T}$. The sample multivariate coefficient of variation $\hat{\gamma}$ is then defined as

$$
\hat{\gamma}_{i}=\left(\overline{\mathbf{X}}^{T} \mathbf{S}^{-1} \overline{\mathbf{X}}\right)^{-\frac{1}{2}}
$$

The c.d.f (cumulative distribution function) and the inverse c.d.f of $\hat{\gamma}$ are given in [12] as

$$
F_{\hat{\gamma}}(x \mid n, p, \delta)=1-F_{F}\left(\frac{n(n-p)}{(n-1) p x^{2}} \mid p, n-p, \delta\right),
$$

and

$$
F_{\hat{\gamma}}^{-1}(\alpha \mid n, p, \delta)=\sqrt{\frac{n(n-p)}{(n-1) p}\left(\frac{1}{F_{F}^{-1}(1-\alpha \mid p, n-p, \delta)}\right)},
$$

where $F_{F}(. \mid p, n-p, \delta)$ and $F_{F}^{-1}(. \mid p, n-p, \delta)$ are the noncentral $F$ distribution and the inverse of the non-central $F$ distribution with $p$ and $n-p$ degrees of freedom, respectively, and the non-centrality parameter is $\delta=n \boldsymbol{\mu}^{T} \boldsymbol{\Sigma}^{-1} \boldsymbol{\mu}=\frac{n}{\gamma^{2}}$.

\section{IMPLEMENTATION OF $\mathrm{RR}_{r, s}-\mathrm{MCV}$ CONTROL CHARTS}

Similar to the one-sided Run Rules control charts presented in [23], [24], we suggest the definition of two one-sided Run Rules control charts for monitoring the MCV as follows:

- A lower-sided $r$-out-of-s Run Rules control chart (denoted as $\mathrm{RR}_{r, s}^{-}-\mathrm{MCV}$ ) to detect a decrease in $\hat{\gamma}_{i}$ with a lower control limit $L C L^{-}$and a corresponding upper control limit $U C L^{-}=+\infty$.

- An upper-sided $r$-out-of-s Run Rules control chart (denoted as $\mathrm{RR}_{r, s}^{+}-\mathrm{MCV}$ ) to detect an increase in $\hat{\gamma}_{i}$ with an upper control limit $U C L^{+}$and a corresponding lower control limit $L C L^{+}=0$.

Given the value of the control limits for each chart, an outof-control signal is given at time $i$ if $r$-out-of- $s$ consecutive $\hat{\gamma}_{i}$ values are plotted outside the control interval, i.e. $\hat{\gamma}_{i}<L C L^{-}$ in the lower-sided chart and $\hat{\gamma}_{i}>U C L^{+}$in the upper-sided chart. The control chart designed above is called pure Run Rules type chart. Compared to the composite Run Rules type charts which require both control and warning limits, these pure type charts are more simple to implement and interpret, see [15]. In this study, we only consider the 2-out-of-3, 3out-of-4 and 4-out-of-5 Run Rules charts. More complex Run Rules schemes with larger values of $(r, s)$ are possible to design in a similar manner. However, their efficiency should increase the complexity in implementation.

The performance of the proposed one-sided $\mathrm{RR}_{r, s}-\mathrm{MCV}$ control charts is measured by the out-of-control $A R L$, denoted as $A R L_{1}$. We utilise a Markov chain method to calculate the $A R L_{1}$ value. Further details on this method can be found in [24]. Let us now suppose that the occurrence of an unexpected condition shifts the in-control MCV value $\gamma_{0}$ to the out-ofcontrol value $\gamma_{1}=\tau \times \gamma_{0}$, where $\tau>0$ is the shift size. Values of $\tau \in(0,1)$ correspond to a decrease of the $\gamma_{0}$, while values of $\tau>1$ correspond to an increase of the in-control $\mathrm{MCV}$. It is worth mentioning that a decrease (resp. increase) in $\gamma_{0}$ is related to process improvement (resp. deterioration). The probability $p$ of the event that a sample falls into an in-control interval is equal to:

- for the $\mathrm{RR}_{r, s}^{-}-\mathrm{MCV}$ chart:

$$
p=P\left(\hat{\gamma}_{i} \geq L C L^{-}\right)=1-F_{\hat{\gamma}}\left(L C L^{-} \mid n, p, \delta_{1}\right),
$$

- for the $\mathrm{RR}_{r, s}^{+}-\mathrm{MCV}$ chart:

$$
p=P\left(\hat{\gamma}_{i} \leq U C L^{+}\right)=F_{\hat{\gamma}}\left(U C L^{+} \mid n, p, \delta_{1}\right),
$$

where $\delta_{1}=\frac{n}{\left(\tau \gamma_{0}\right)^{2}}$.

The Transition Probability Matrix $\mathbf{P}$ of the embedded Markov chain for the two $\mathrm{RR}_{2,3}-\mathrm{MCV}$ control charts is

$$
\mathbf{P}=\left(\begin{array}{cc}
\mathbf{Q} & \mathbf{r} \\
& \\
\mathbf{0}^{T} & 1
\end{array}\right)=\left(\begin{array}{ccc|c}
0 & 0 & p & 1-p \\
p & 0 & 0 & 1-p \\
0 & 1-p & p & 0 \\
\hline 0 & 0 & 0 & 1
\end{array}\right)
$$

where $\mathbf{Q}$ is the $(3,3)$ matrix of transient probabilities, $\mathbf{r}$ is the $(3,1)$ vector satisfied $\mathbf{r}=\mathbf{1}-\mathbf{Q} \mathbf{1}$ with $\mathbf{1}=(1,1,1)^{T}$ and 
$\mathbf{0}=(0,0,0)^{T}$. The corresponding $(3,1)$ vector $\mathbf{q}$ of initial probabilities associated with the transient states is equal to $\mathbf{q}=(0,0,1)^{T}$, i.e. the third state is the initial state.

Extended to Run Rules charts with larger $(r, s)$ values, the matrix $\mathbf{Q}_{(7 \times 7)}$ of transient probabilities for the two $\mathrm{RR}_{3,4}-\mathrm{MCV}$ control charts is given by

$$
\mathbf{Q}=\left(\begin{array}{ccccccc}
0 & 0 & p & 0 & 0 & 0 & 0 \\
0 & 0 & 0 & 0 & p & 0 & 0 \\
0 & 0 & 0 & 0 & 0 & 1-p & p \\
p & 0 & 0 & 0 & 0 & 0 & 0 \\
0 & 1-p & p & 0 & 0 & 0 & 0 \\
0 & 0 & 0 & 1-p & p & 0 & 0 \\
0 & 0 & 0 & 0 & 0 & 1-p & p
\end{array}\right) .
$$

In this case, the seventh state in the vector $\mathbf{q}=$ $(0,0,0,0,0,0,1)^{T}$ is the initial state. The $(15,15)$ matrix $\mathbf{Q}$ of transient probabilities for the two $\mathrm{RR}_{4,5}-\mathrm{MCV}$ control charts can be found in [23]. Once matrix $\mathbf{Q}$ and vector $\mathbf{q}$ have been determined, the $A R L$ and $S D R L$ (standard deviation of run length) are obtained by:

$$
A R L=\nu_{1}, \text { and } S D R L=\sqrt{\mu_{2}},
$$

with

$$
\begin{aligned}
\nu_{1} & =\mathbf{q}^{T}(\mathbf{I}-\mathbf{Q})^{-1} \mathbf{1} \\
\nu_{2} & =2 \mathbf{q}^{T}(\mathbf{I}-\mathbf{Q})^{-2} \mathbf{Q} \mathbf{1} \\
\mu_{2} & =\nu_{2}-\nu_{1}^{2}+\nu_{1} .
\end{aligned}
$$

A control chart is considered to be better than its competitors if it gives smaller value of the $A R L_{1}$ while the $A R L_{0}$ is the same. Therefore, the control limit of the $\mathrm{RR}_{r, s}-\mathrm{MCV}$ control charts should be found out as a solution of the following equations:

- for the $\mathrm{RR}_{r, s}^{-}-\mathrm{MCV}$ chart:

$$
A R L\left(L C L^{-}, n, p, \gamma_{0}, \tau=1\right)=A R L_{0},
$$

- for the $\mathrm{RR}_{r, s}^{+}-\mathrm{MCV}$ chart:

$$
A R L\left(U C L^{+}, n, p, \gamma_{0}, \tau=1\right)=A R L_{0},
$$

where $A R L_{0}$ is the predetermined in-control $A R L$ value.

\section{Performance of the $\mathrm{RR}_{r, s}$-MCV CONTROL CHARTS}

We investigate the performance of the $\mathrm{RR}{ }_{r, s}-\mathrm{MCV}$ control charts. The desired in-control $A R L$ value, say $A R L_{0}$ is set at 370.4 , for all the considered IC cases. In Figure 1, we present the $A R L$ profiles for both the Shewhart chart (designed by [12]) and the Run Rules charts for a number of different in-control scenarios. Since the $A R L$ curves for the upper case overlap each other, we include the ARL curves for $\tau \geq 1.2$ as an inset plot. The Figure 1 shows that for the lower case (decrease shifts), the 4-of-5 Run Rule chart remarkably outperforms the Shewhart chart and the other Run Rules charts, especially when $n=5, p=2$ and $\gamma_{0}=0.1$. As $n, p, \gamma_{0}$ increase, the improvement is not as much as in the first case but still, it is substantial. For upper case (increase shifts), we have also an improvement with Run Rules charts but it is not as much as in the lower case. In addition, a part of the $A R L$ curve of the Shewhart chart corresponding to very large shifts (i.e., 1.50 or 0.50 ) is below $A R L$ curves of Run Rules charts. We deduce that the Shewhart chart becomes more efficient than the proposed Run Rule based charts in detecting very large shifts.

The analysis presented above is only for the case of specific shift size. In practice, however, it is hard for quality practitioners to predetermine a specific shift without any previous experience. Thus, they usually have an interest in detecting a range of shifts $\tau \in[a, b]$ rather than preference for any particular size of the process shift. The use of the uniform distribution has been proposed to account for the unknown shift size by some authors, see [25]. The statistical performance of the corresponding chart can be evaluated through the EARL (Expected Average Run Length) given by

$$
E A R L=\int_{a}^{b} A R L(\tau) \times f_{\tau}(\tau) d \tau,
$$

where $A R L(\tau)$ is the $A R L$ function of shift $\tau$, and $f_{\tau}(\tau)=$ $\frac{1}{b-a}$ for $\tau \in[a, b]$. In the following section, we will consider a specific range of shift $[a, b]=[0.5,1)$ (decreasing case, denoted as (D)) for lower-sided $\mathrm{RR}_{r, s}-\mathrm{MCV}$ control chart and $[a, b]=(1,2]$ (increasing case, denoted as (I)) for uppersided $\mathrm{RR}_{r, s}-\mathrm{MCV}$ control chart.

Table I presents the values of EARL and ESDRL (Expected Standard Deviation Run Length) for various combinations of $n=\{5,10,15\}, \gamma_{0}=\{0.1,0.2,0.3,0.4\}$ and $p=\{2,3,4\}$. The same trends as the case of specific shift size are observed from this table. The value of $E A R L$ in the upper-sided Run Rule control chart corresponding to smaller values of $(r, s)$ is significantly smaller than that corresponding to larger values of $(r, s)$. In the contrary, the values of $E A R L$ decrease from smaller $(r, s)$ scheme to larger $(r, s)$ scheme of Run Rules for lower-sided chart. Therefore, the choice of using $\mathrm{RR}_{2,3}-\mathrm{MCV}, \mathrm{RR}_{3,4}-\mathrm{MCV}$ or $\mathrm{RR}_{4,5 s}-\mathrm{MCV}$ control charts depends on the goal of practitioners: if they want to detect increasing shifts, they are advised to choose smaller $(r, s)$ scheme of Run Rules (say $\mathrm{RR}_{2,3}-\mathrm{MCV}$ in this paper); otherwise, the larger $(r, s)$ scheme of Run Rules (say $\mathrm{RR}_{4,5}-\mathrm{MCV}$ ) should be used.

In comparison with the Run Sum MCV control chart suggested by [13], the Run Rules based charts also have some outstanding advantages. Even so, the global performance of the Run Rules charts is still better than that of the Run Sum chart. In particular, with $n=5, \gamma_{0}=0.1$ and $p=2$, for the upward chart we have $E A R L=29.4$ in the $\mathrm{RR}_{2.3}^{+}-\mathrm{MCV}$ chart in this paper while $E A R L=31.37$ in the Run Sum control chart (Table 1 in [13]); for the downward we have $E A R L=67.9$ in the $\mathrm{RR}_{4.5}^{-}-\mathrm{MCV}$ chart while $E A R L=70.49$ in the Run Sum control chart (Table 3 in [13]). As mentioned above, the use of the Run Sum control chart requires to optimise the score vectors over a range of shifts that is difficult to predetermine exactly in practice. When the predetermined value of the shift 


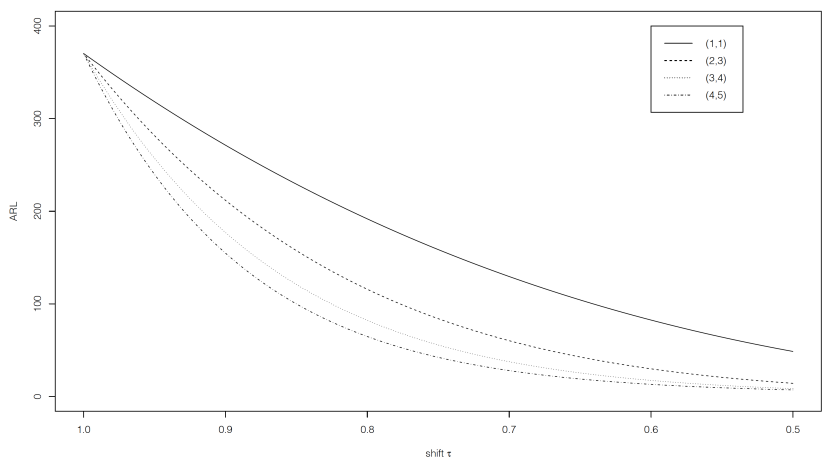

(a) $p=2, n=5, \gamma_{0}=0.1$

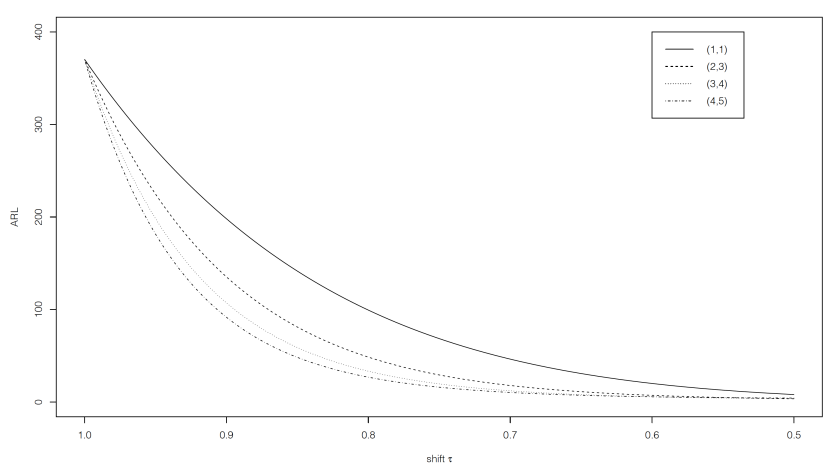

(c) $p=3, n=10, \gamma_{0}=0.3$

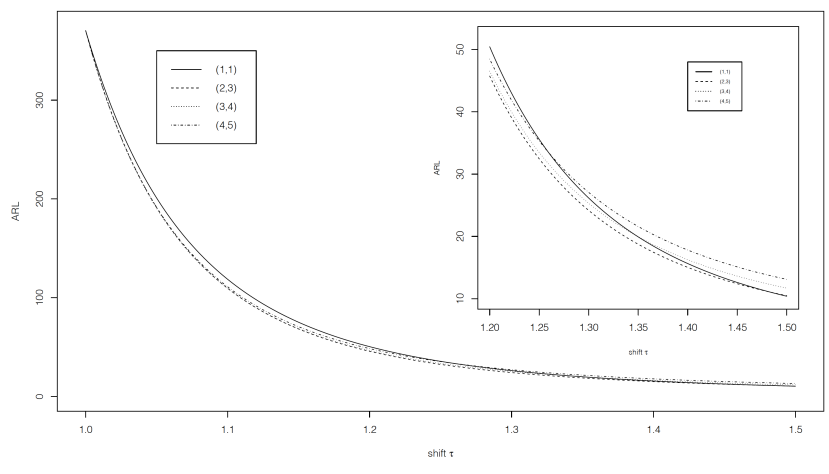

(b) $p=2, n=5, \gamma_{0}=0.1$

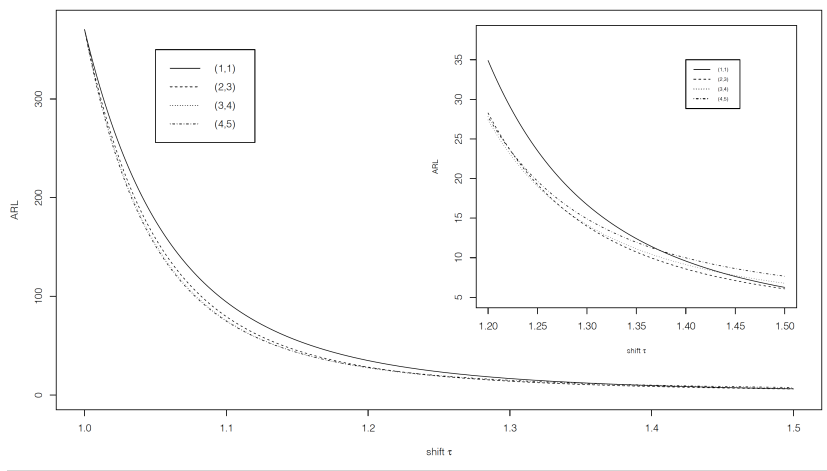

(d) $p=3, n=10, \gamma_{0}=0.3$

Fig. 1: The $A R L$ profiles of Shewhart chart and Run Rules charts for various in-control settings; left side: lower-sided charts, right side: upper-sided charts.

size $\tau$ is different from the true shift size, the run-length properties of the designed control chart could be seriously affected [5]. Meanwhile, the Run Rules charts only need the determination of a single control limit value for all shift sizes. This makes the Run Rules MCV chart easier to implement.

\section{CONCLUDING REMARKS}

In this paper, we have investigated the one-sided control charts with Run Rules for monitoring the coefficient of variation of multivariate data. Two one-sided charts were considered to detect separately both increases and decreases in the multivariate $\mathrm{CV}$. The performance of proposed charts is evaluated through $A R L$ for deterministic shift size and $E A R L$ for unknown shift size. The numerical results showed that the Run Rules control charts enhance the performance of Shewhart control chart significantly. For purpose of optimising the performance of Run Rules charts, it is recommended to use the $\mathrm{RR}_{4,5}^{-}-\mathrm{MCV}$ for detecting decreasing process shifts and $\mathrm{RR}_{2,3}^{+}-\mathrm{MCV}$ for detecting increasing process shifts. Moreover, under certain conditions, this careful choice of the Run Rules charts also lead to an improved efficiency compared to the Run Sum control chart for MCV.

\section{REFERENCES}

[1] Q. T. Nguyen, K. P. Tran, P. Castagliola, T. T. Huong, M. K. Nguyen, and S. Lardjane, "Nested one-class support vector machines for network intrusion detection," in 2018 IEEE Seventh International Conference on Communications and Electronics (ICCE). IEEE, 2018, pp. 7-12.

[2] V. Vuong Trinh, K. Phuc Tran, and T. Thu Huong, "Data driven hyperparameter optimization of one-class support vector machines for anomaly detection in wireless sensor networks," in 2017 International Conference on Advanced Technologies for Communications (ATC), Oct 2017, pp. 6-10.

[3] V. Chandola, A. Banerjee, and V. Kumar, "Anomaly detection: A survey," ACM computing surveys (CSUR), vol. 41, no. 3, pp. 1-58, 2009.

[4] W. Shewhart, Economic Control of Quality of Manufactured Product. Van Nostrand, New York, 1931.

[5] K. P. Tran, H. D. Nguyen, P. H. Tran, and C. Heuchenne, "On the performance of cusum control charts for monitoring the coefficient of variation with measurement errors," The International Journal of Advanced Manufacturing Technology, pp. 1-15, 2019.

[6] W. Teoh, M. Khoo, P. Castagliola, W. Yeong, and S. Teh, "Run-sum control charts for monitoring the coefficient of variation," European Journal of Operational Research, vol. 257, no. 1, pp. 144-158, 2017.

[7] T. P. Hanh, "One-sided run rules control charts for coefficient of variation with measurement errors," in Proceedings of ISSAT International Conference on Data Science in Business, Finance and Industry (DSBFI 2019), 2019, pp. 31-35.

[8] T. H. Truong, P. B. Ta, Q. T. Nguyen, H. Du Nguyen, and K. P. Tran, "A data-driven approach for network intrusion detection and monitoring based on kernel null space," in International Conference on Industrial Networks and Intelligent Systems. Springer, 2019, pp. 130-140. 
TABLE I: The values $\left(E A R L_{1}, E S D R L_{1}\right)$ for $R R_{r, s}^{-}-\mathrm{MCV}$ control chart when $[a, b]=[0.5,1)$ and for $\mathrm{RR}_{r, s}^{+}-\mathrm{MCV}$ control chart when $[a, b]=(1,2]$ with different values of $p, n, \gamma_{0}$ and $\tau$.

\begin{tabular}{|c|c|c|c|c|c|c|c|c|c|}
\hline \multirow[b]{3}{*}{$\tau$} & \multicolumn{9}{|c|}{$p=2$} \\
\hline & \multicolumn{3}{|c|}{$\mathrm{RR}_{2,3}-\mathrm{MCV}$ chart } & \multicolumn{3}{|c|}{$\begin{array}{c}\mathrm{RR}_{3,4} \text {-MCV chart } \\
p=2\end{array}$} & \multicolumn{3}{|c|}{$\mathrm{RR}_{4,5}-\mathrm{MCV}$ chart } \\
\hline & $n=5$ & $n=10$ & $n=15$ & $n=5$ & $n=10$ & $n=15$ & $n=5$ & $n=10$ & $n=15$ \\
\hline (D) & $(101.8,100.1)$ & $(48.1,46.5)$ & $(33.0,31.3)$ & $(79.4,76.7)$ & $\begin{array}{l}\gamma_{0}=0.1 \\
(38.5,36.0)\end{array}$ & $(26.9,24.3)$ & $(67.8,64.4)$ & $(34.0,30.6)$ & $(24.2,20.7)$ \\
\hline (I) & $(29.4,27.8)$ & $(17.4,15.8)$ & $(13.2,11.5)$ & $(30.3,27.9)$ & $(17.4,15.0)$ & $(13.1,10.6)$ & $(31.7,28.5)$ & $(18.0,14.7)$ & $(13.7,10.2)$ \\
\hline $\begin{array}{l}\text { (D) } \\
\text { (I) }\end{array}$ & $\begin{array}{c}(103.1,101.3) \\
(30.3,28.6)\end{array}$ & $\begin{array}{l}(49.2,47.5) \\
(18.1,16.5)\end{array}$ & $\begin{array}{l}(33.9,32.2) \\
(13.7,12.1)\end{array}$ & $\begin{array}{l}(80.4,77.8) \\
(31.2,28.7)\end{array}$ & $\begin{array}{l}\gamma_{0}=0.2 \\
(39.4,36.9) \\
(18.1,15.6)\end{array}$ & $\begin{array}{l}(27.6,25.1) \\
(13.6,11.1)\end{array}$ & $\begin{array}{l}(68.8,65.4) \\
(32.6,29.3)\end{array}$ & $\begin{array}{l}(34.8,31.4) \\
(18.6,15.3)\end{array}$ & $\begin{array}{l}(24.9,21.4) \\
(14.1,10.7)\end{array}$ \\
\hline $\begin{array}{l}\text { (D) } \\
\text { (I) }\end{array}$ & $\begin{array}{c}(105.1,103.3) \\
(31.8,30.1)\end{array}$ & $\begin{array}{l}(50.9,49.2) \\
(19.2,17.7)\end{array}$ & $\begin{array}{l}(35.3,33.7) \\
(14.6,13.0)\end{array}$ & $\begin{array}{l}(82.2,79.6) \\
(32.6,30.1)\end{array}$ & $\begin{array}{l}\gamma_{0}=0.3 \\
(40.9,38.4) \\
(19.1,16.7)\end{array}$ & $\begin{array}{l}(28.8,26.3) \\
(14.5,12.0)\end{array}$ & $\begin{array}{l}(70.4,67.0) \\
(34.0,30.8)\end{array}$ & $\begin{array}{l}(36.1,32.7) \\
(19.6,16.3)\end{array}$ & $\begin{array}{l}(26.0,22.5) \\
(14.9,11.5)\end{array}$ \\
\hline $\begin{array}{l}\text { (D) } \\
\text { (I) }\end{array}$ & $\begin{array}{c}(107.8,106.1) \\
(34.0,32.4)\end{array}$ & $\begin{array}{l}(53.2,51.5) \\
(20.9,19.3)\end{array}$ & $\begin{array}{l}(37.2,35.6) \\
(15.9,14.3)\end{array}$ & $\begin{array}{l}(84.7,82.0) \\
(34.7,32.3)\end{array}$ & $\begin{array}{c}\gamma_{0}=0.4 \\
(42.9,40.3) \\
(20.6,18.1)\end{array}$ & $\begin{array}{l}(30.5,27.9) \\
(15.6,13.1)\end{array}$ & $\begin{array}{l}(72.6,69.2) \\
(36.1,32.9)\end{array}$ & $\begin{array}{l}(37.9,34.5) \\
(21.1,17.8)\end{array}$ & $\begin{array}{l}(27.4,24.0) \\
(16.0,12.6)\end{array}$ \\
\hline \multirow{2}{*}{ (I) } & \multicolumn{9}{|c|}{$p=3$} \\
\hline & \multicolumn{3}{|c|}{$\mathrm{RR}_{2,3}$-MCV chart } & \multicolumn{3}{|c|}{$\mathrm{RR}_{3,4}-\mathrm{MCV}$ chart } & \multicolumn{3}{|c|}{$\mathrm{RR}_{4,5}$-MCV chart } \\
\hline$\tau$ & $n=5$ & $n=10$ & $n=15$ & $n=5$ & $n=10$ & $n=15$ & $n=5$ & $n=10$ & $n=15$ \\
\hline $\begin{array}{l}\text { (D) } \\
\text { (I) }\end{array}$ & $\begin{array}{c}(136.9,135.1) \\
(36.0,34.3)\end{array}$ & $\begin{array}{l}(53.3,51.7) \\
(18.8,17.2)\end{array}$ & $\begin{array}{l}(35.1,33.5) \\
(13.8,12.2)\end{array}$ & $\begin{array}{c}(107.0,104.3) \\
(37.9,35.4)\end{array}$ & $\begin{array}{l}\gamma_{0}=0.1 \\
(42.5,40.0) \\
(18.8,16.4)\end{array}$ & $\begin{array}{l}(28.5,26.0) \\
(13.8,11.2)\end{array}$ & $\begin{array}{l}(90.6,87.2) \\
(40.2,36.9)\end{array}$ & $\begin{array}{l}(37.3,34.0) \\
(19.5,16.2)\end{array}$ & $\begin{array}{l}(25.6,22.1) \\
(14.3,10.9)\end{array}$ \\
\hline $\begin{array}{l}\text { (D) } \\
\text { (I) }\end{array}$ & $\begin{array}{c}(138.3,136.5) \\
(37.0,35.4)\end{array}$ & $\begin{array}{l}(54.5,52.8) \\
(19.5,17.9)\end{array}$ & $\begin{array}{l}(36.1,34.4) \\
(14.4,12.8)\end{array}$ & $\begin{array}{c}(108.3,105.6) \\
(38.9,36.4)\end{array}$ & $\begin{array}{l}\gamma_{0}=0.2 \\
(43.5,41.0) \\
(19.5,17.1)\end{array}$ & $\begin{array}{l}(29.3,26.8) \\
(14.3,11.8)\end{array}$ & $\begin{array}{l}(91.8,88.3) \\
(41.2,38.0)\end{array}$ & $\begin{array}{l}(38.2,34.8) \\
(20.1,16.8)\end{array}$ & $\begin{array}{l}(26.3,22.9) \\
(14.8,11.4)\end{array}$ \\
\hline $\begin{array}{l}\text { (D) } \\
\text { (I) }\end{array}$ & $\begin{array}{c}(140.6,138.8) \\
(38.8,37.2)\end{array}$ & $\begin{array}{l}(56.3,54.7) \\
(20.7,19.2)\end{array}$ & $\begin{array}{l}(37.6,35.9) \\
(15.3,13.7)\end{array}$ & $\begin{array}{c}(110.3,107.6) \\
(40.7,38.2)\end{array}$ & $\begin{array}{l}\gamma_{0}=0.3 \\
(45.1,42.5) \\
(20.7,18.2)\end{array}$ & $\begin{array}{l}(30.6,28.0) \\
(15.2,12.7)\end{array}$ & $\begin{array}{l}(93.7,90.2) \\
(43.1,39.8)\end{array}$ & $\begin{array}{l}(39.6,36.3) \\
(21.2,18.0)\end{array}$ & $\begin{array}{l}(27.4,24.0) \\
(15.6,12.3)\end{array}$ \\
\hline $\begin{array}{l}\text { (D) } \\
\text { (I) }\end{array}$ & $\begin{array}{c}(143.6,141.8) \\
(41.6,40.0)\end{array}$ & $\begin{array}{l}(58.8,57.1) \\
(22.5,20.9)\end{array}$ & $\begin{array}{l}(39.6,37.9) \\
(16.7,15.1)\end{array}$ & $\begin{array}{c}(113.2,110.5) \\
(43.4,40.9)\end{array}$ & $\begin{array}{l}\gamma_{0}=0.4 \\
(47.2,44.7) \\
(22.3,19.8)\end{array}$ & $\begin{array}{l}(32.3,29.8) \\
(16.4,13.9)\end{array}$ & $\begin{array}{l}(96.4,92.9) \\
(45.8,42.5)\end{array}$ & $\begin{array}{l}(41.5,38.2) \\
(22.8,19.6)\end{array}$ & $\begin{array}{l}(29.0,25.6) \\
(16.8,13.4)\end{array}$ \\
\hline \multirow{2}{*}{ (I) } & \multicolumn{9}{|c|}{$p=4$} \\
\hline & \multicolumn{3}{|c|}{$\mathrm{RR}_{2,3}-\mathrm{MCV}$ chart } & \multicolumn{3}{|c|}{$\mathrm{RR}_{3,4}$-MCV chart } & \multicolumn{3}{|c|}{$\mathrm{RR}_{4,5}$-MCV chart } \\
\hline$\tau$ & $n=5$ & $n=10$ & $n=15$ & $n=5$ & $n=10$ & $n=15$ & $n=5$ & $n=10$ & $n=15$ \\
\hline $\begin{array}{l}\text { (D) } \\
\text { (I) }\end{array}$ & $\begin{array}{c}(208.8,206.9) \\
(50.0,48.3)\end{array}$ & $\begin{array}{l}(60.1,58.4) \\
(20.5,18.9)\end{array}$ & $\begin{array}{l}(37.6,35.9) \\
(14.5,12.9)\end{array}$ & $\begin{array}{c}(171.7,168.9) \\
(55.1,52.6)\end{array}$ & $\begin{array}{l}\gamma_{0}=0.1 \\
\quad(47.6,45.1) \\
(20.6,18.1)\end{array}$ & $\begin{array}{l}(30.4,27.9) \\
(14.5,12.0)\end{array}$ & $\begin{array}{c}(147.1,143.5) \\
(60.3,57.0)\end{array}$ & $\begin{array}{l}(41.6,38.2) \\
(21.3,18.0)\end{array}$ & $\begin{array}{l}(27.2,23.8) \\
(15.0,11.6)\end{array}$ \\
\hline $\begin{array}{l}\text { (D) } \\
\text { (I) }\end{array}$ & $\begin{array}{c}(210.1,208.2) \\
(51.4,49.7)\end{array}$ & $\begin{array}{l}(61.3,59.6) \\
(21.3,19.7)\end{array}$ & $\begin{array}{l}(38.6,36.9) \\
(15.1,13.5)\end{array}$ & $\begin{array}{c}(173.1,170.3) \\
(56.6,54.1)\end{array}$ & $\begin{array}{l}\gamma_{0}=0.2 \\
\quad(48.7,46.2) \\
(21.3,18.9)\end{array}$ & $\begin{array}{l}(31.3,28.7) \\
(15.0,12.5)\end{array}$ & $\begin{array}{c}(148.5,144.9) \\
(61.9,58.5)\end{array}$ & $\begin{array}{l}(42.5,39.2) \\
(22.0,18.7)\end{array}$ & $\begin{array}{l}(27.9,24.5) \\
(15.6,12.2)\end{array}$ \\
\hline $\begin{array}{l}\text { (D) } \\
\text { (I) }\end{array}$ & $\begin{array}{c}(212.3,210.4) \\
(53.9,52.2)\end{array}$ & $\begin{array}{l}(63.3,61.6) \\
(22.6,21.0)\end{array}$ & $\begin{array}{l}(40.2,38.5) \\
(16.1,14.5)\end{array}$ & $\begin{array}{c}(175.4,172.6) \\
(59.2,56.7)\end{array}$ & $\begin{array}{l}\gamma_{0}=0.3 \\
(50.4,47.9) \\
(22.6,20.2)\end{array}$ & $\begin{array}{l}(32.6,30.1) \\
(16.0,13.5)\end{array}$ & $\begin{array}{c}(150.8,147.2) \\
(64.7,61.2)\end{array}$ & $\begin{array}{l}(44.1,40.7) \\
(23.3,20.0)\end{array}$ & $\begin{array}{l}(29.2,25.7) \\
(16.4,13.1)\end{array}$ \\
\hline $\begin{array}{l}\text { (D) } \\
\text { (I) }\end{array}$ & $\begin{array}{c}(215.2,213.4) \\
(57.7,56.0)\end{array}$ & $\begin{array}{l}(66.0,64.3) \\
(24.5,22.9)\end{array}$ & $\begin{array}{l}(42.3,40.6) \\
(17.6,16.0)\end{array}$ & $\begin{array}{c}(178.6,175.8) \\
(63.1,60.5)\end{array}$ & $\begin{array}{l}\gamma_{0}=0.4 \\
\quad(52.7,50.2) \\
(24.4,22.0)\end{array}$ & $\begin{array}{l}(34.4,31.9) \\
(17.3,14.8)\end{array}$ & $\begin{array}{c}(154.0,150.4) \\
(68.7,65.3)\end{array}$ & $\begin{array}{l}(46.2,42.8) \\
(25.0,21.8)\end{array}$ & $\begin{array}{l}(30.8,27.4) \\
(17.7,14.4)\end{array}$ \\
\hline
\end{tabular}

[9] R. Noorossana, S. S. Hosseini, and A. Heydarzade, "An overview of dynamic anomaly detection in social networks via control charts," Quality and Reliability Engineering International, vol. 34, no. 4, pp 641-648, 2018.

[10] C. Kang, M. Lee, Y. Seong, and D. Hawkins, "A control chart for the coefficient of variation," Journal of Quality Technology, vol. 39, no. 2, pp. 151-158, 2007.

[11] A. Albert and L. Zhang, "A novel definition of the multivariate coefficient of variation," Biometrical Journal, vol. 52, no. 5, pp. 667-675, 2010.

[12] W. Yeong, M. B. C. Khoo, W. L.Teoh, and P. Castagliola, "A control chart for the multivariate coefficient of variation," Quality and Reliability Engineering International, vol. 32, no. 3, pp. 1213-1225, 2016.

[13] A. Lim, M. Khoo, W. Teoh, and A. Haq, "Run sum chart for monitoring multivariate coefficient of variation," Computers \& Industrial Engineering, vol. 109, pp. 84-95, 2017.

[14] Q. T. Nguyen, K. P. Tran, P. Castagliola, G. Celano, and S. Lardjane, "One-sided synthetic control charts for monitoring the multivariate coefficient of variation," Journal of Statistical Computation and Simulation, vol. 89, no. 10, pp. 1841-1862, 2019.

[15] M. Klein, "Two Alternatives to the Shewhart $\bar{X}$ Control Chart," Journal of Quality Technology, vol. 32, pp. 427-431, 2000.

[16] M. Khoo, "Design of Runs Rules Schemes," Quality Engineering, vol. 16, no. 2, pp. 27-43, 2004.

[17] M. Koutras, S. Bersimis, and P. Maravelakis, "Statistical process control using shewhart control charts with supplementary runs rules," Methodology and Computing in Applied Probability, vol. 9, pp. 207-224, 2007.
[18] D. Antzoulakos and A. Rakitzis, "The Modified $r$ out of $m$ Control Chart," Communications in Statistics - Simulation and Computation, vol. 37, no. 2, pp. 396-408, 2008.

[19] X. Y. Chew, K. W. Khaw, and W. C. Yeong, "The efficiency of run rules schemes for the multivariate coefficient of variation: a markov chain approach," Journal of Applied Statistics, pp. 1-21, 2019.

[20] K. P. Tran, "The efficiency of the 4-out-of-5 runs rules scheme for monitoring the ratio of population means of a bivariate normal distribution," International Journal of Reliability, Quality and Safety Engineering, vol. 23, no. 05, p. 1650020, 2016.

[21] R. A. Reyment, Studies on Nigerian Upper Cretaceous and Lower Tertiary Ostracoda. P. 1, Senonian and Maestrichtian Ostracoda, ser. Stockholm contributions in geology, 1960, no. 7.

[22] M. Nikulin and V. Voinov, "Unbiased estimators and their applications," in International Encyclopedia of Statistical Science. Springer, 2011, pp. 1619-1621

[23] K. Tran, P. Castagliola, and G. Celano, "Monitoring the Ratio of Two Normal Variables Using Run Rules Type Control Charts," International Journal of Production Research, vol. 54, no. 6, pp. 1670-1688, 2016.

[24] P. Castagliola, A. Achoure, H. Taleb, G. Celano, and S. Psarakis, "Monitoring the coefficient of variation using control charts with run rules," Quality Technology \& Quantitative Management, vol. 10, pp. 75-94, 2013.

[25] A. Chen and Y. K. Chen, "Design of EWMA and CUSUM control charts subject to random shift sizes and quality impacts," IIE Transactions, vol. 39 , no. 12, pp. 1127-1141, 2007. 